\title{
Networks of prey specialization in an Arctic monomorphic seabird
}

\author{
Jennifer F. Provencher, Kyle H. Elliott, Anthony J. Gaston and Birgit M. Braune \\ J. F. Provencher (jennifer.provencher@ec.gc.ca), Dept of Biology, Carleton Univ., Ottawa, ON K1A 0H3, Canada. - K. H. Elliott, Dept of \\ Biological Sciences, Univ. of Manitoba, Winnipeg, MB R3T 2N2, Canada. - A. J. Gaston and B. M. Braune, National Wildlife Research Centre, \\ Carleton Univ., Ottawa, ON K1A OH3, Canada.
}

\begin{abstract}
Generalist predator populations are sometimes made up of individuals that specialize on particular prey items. To examine specialization in thick-billed murres Uria lomvia during self-feeding we obtained stomach contents and muscle stable isotope values for 213 birds feeding close to five colonies in the Canadian Arctic. Adults were less specialized during selffeeding than during chick-provisioning. Nonetheless, particular specialists clustered together within the foraging network. While sexes showed similar levels of specialization, individuals of the same sex clustered together within the foraging network. The significant degree of clustering regardless of sex showed that individuals specializing on one prey item tend to also specialize on another, although network topology varied from colony to colony. Adult muscle stable isotope values correlated with the stable isotope values of the prey found in stomachs, at least at the one colony with relevant prey data, suggesting that specializations are maintained over time. Degree of specialization increased with niche width across the five colonies, but similarity in gastro-intestinal and bill morphology was independent of dietary similarity. Thus, although individual specialization is thought to play a key role in sympatric speciation through trophic specialization, we found no support for an association between morphology and foraging patterns in our species. We conclude that self-feeding murres show clustered dietary specialization, and that specialization is highest where diet is most diverse.
\end{abstract}

Early formulations of foraging theory treated predators as opportunists, randomly encountering each prey item (optimal foraging theory - MacArthur and Pianka 1966, information centre hypothesis - Ward and Zahavi 1973, central-place foraging - Orians and Pearson 1979, seabirds as indicators - Cairns 1987). However, we now know that foraging specialization is widespread among animals, with some generalist populations comprising a variety of specialists (Bolnick et al. 2003). We also know that the distribution of prey in discrete environments can be an important route to specialization, especially the benthic-pelagic dichotomy in aquatic environments (Elliott et al. 2008, 2009a, b, Garduño-Paz and Adams 2010). Individual predators may specialize on a single location, habitat or prey type, and these specializations influence prey encounter rates (Bolnick et al. 2003, Elliott et al. 2008, 2009a, c, Woo et al. 2008). Because animals are not just random samplers of their environment, individual decision-making is an important component of understanding what dietary trends indicate at the population level.

Individual specialization may play a role in sympatric speciation when niche expansion occurs through increased inter-individual variation (Bolnick et al. 2007, Araújo et al. 2009). Specifically, the niche variation hypothesis states that inter-individual variation in diet increases with niche width, leading to adaptive radiation as new niches are colonized (Van Valen 1965, Bolnick et al. 2007). Woo et al. (2008) speculated that diversification of sympatric seabirds may be partially linked to such a mechanism and such diversification may occur when groups of birds specialize on different sections of the prey field, and may not be accurately represented by a simple specialist-generalist dichotomy.

Although individuals specializing on different prey items may have very different traits, most studies focus on a single specialist-generalist dichotomy (Bolnick et al. 2003, Woo et al. 2008). However, several methods can be used to go beyond a single specialist - generalist dichotomy and to examine the degree of similarity among individuals, including k-means clustering, multivariate discriminant analyses and network theory. Although more computationally intense than other techniques, network theory generally provides a more robust index of clustering than earlier methods (Hruschka and Natter 1997, Jain 2009, Cohen and Havlin 2010). In particular, network theory provides a method for understanding the linkages between different specialists, with more linkages among individuals representing a set of specialists, potentially overcoming some of the difficulties inherent in a single specialist-generalist index as described by Araújo et al. $(2008,2010)$. Individuals are represented as vertices within the network and the degree of similarity between any two individuals - their pairwise overlap in diet - is represented by the coefficient on each edge. Individuals with no dietary overlap would not be connected via an edge and individuals with complete dietary overlap would have a coefficient of one. If particular specializations 
tend to overlap, then individuals will tend to cluster together within the network.

Dietary specialization in seabirds may affect physical traits that influence, and may be influenced by, prey type. Several studies have found differences in foraging behaviour in sexually dimorphic species, suggesting that these differences may be mediated by their sexual dimorphism, with the larger sex diving deeper, flying farther or excluding the other sex (Weimerskirch et al. 1997, Gonzales-Solis et al. 2000). Less attention has been given to why birds that are monomorphic also show specialization (Lewis et al. 2002, Woo et al. 2008, Elliott et al. 2010). When the two sexes do not physically differ significantly from each other, how does gender-based specialization occur within the population?

To test the ideas that specialization occurs within clustered subsets (foraging groups) of a larger diet network (e.g. within a colony) due to geographical segregation of foraging locations, and that these geographic separations may represent differences in diet between sexes, we examined specialization in a marine predator, the thick-billed murre (Uria lomvia; from here on referred to simply as murre). Murres are monomorphic, circumpolar seabirds that feed on a variety of fish and invertebrates (Gaston and Nettleship 1981, Gaston and Bradstreet 1993). In the Canadian Arctic murres forage within $100 \mathrm{~km}$ of the breeding colonies, with colonies several hundred kilometers away from each other, creating foraging zones specific to each breeding location (Gaston and Hipfner 2000). Murre foraging studies in the eastern Canadian Arctic have shown that both specialists and generalists exist in the population, and that specialization occurs on a number of different prey groups (Elliott et al. 2009c).

We used murres collected as part of a historical dietary analysis carried out during the International Polar Year (2007-2009; Provencher et al. 2010, 2012) to study patterns of individual specialization in murres. Along with the diet information associated with each bird, we obtained detailed geographic information, external and gastro-intestinal metrics, and stable isotope values from breast muscle. We used these data to investigate 1) whether individual specialization occurs in self-feeding birds, 2) whether apparent specialization can be accounted for by sex, as observed by Elliott et al. (2010), or physical traits; 3) whether specialization is greater in colonies where diet breadth is larger, as predicted by the niche variation hypothesis (Van Valen 1965, Bolnick et al. 2007); and 4) how specialization relates to carbon and nitrogen isotope signatures for muscle tissue, assumed to be a longer term dietary signature.

\section{Material and methods}

\section{Stomach contents analysis}

Detailed collection methods are given by (Provencher et al. 2010, 2012). Briefly, adult murres were shot with a 12 gauge shotgun in areas where they were actively feeding within $30 \mathrm{~km}$ of the colony. Collections were made during the 2007/2008/2009 chick-rearing seasons (one collection per year) in the waters around five breeding colonies: Akpatok Island $\left(60^{\circ} 25^{\prime} \mathrm{N}, 68^{\circ} 08^{\prime} \mathrm{W}\right)$, Coats Island $\left(62^{\circ} 57^{\prime} \mathrm{N}, 82^{\circ} 00^{\prime} \mathrm{W}\right)$, Digges Sound $\left(62^{\circ} 33^{\prime} \mathrm{N}, 77^{\circ} 35^{\prime} \mathrm{W}\right)$, the Minarets (also known as Akpait; $66^{\circ} 56^{\prime} \mathrm{N}, 61^{\circ} 46^{\prime} \mathrm{W}$ ) and Prince Leopold Island $\left(74^{\circ} 02^{\prime} \mathrm{N}, 90^{\circ} 00^{\prime} \mathrm{W}\right.$; one collection also during pre-laying) (Fig. 1, Table 1). At Digges Sound birds collected during the chick-rearing season were collected from several areas around this large colony, including Nuvuk Harbour $(\mathrm{n}=30)$, Cape Wolstenholm $(\mathrm{n}=32)$ and Hudson Bay $(\mathrm{n}=29)$ (Fig. 2). Diet was similar across years for birds sampled at the same site in multiple years. Since the shortest distance between any of the colonies $(220 \mathrm{~km})$ was greater than the normal foraging range of this species ( $100 \mathrm{~km}$, Gaston and Hipfner 2000) each bird collected is assumed to have originated from the local colony.

The entire gastro-intestinal tract (GIT), from oesophagus to cloaca was removed from each bird. Once opened, the stomach was flushed to remove dietary items, taking care to remove all items in the folds of the stomach, and placed in 95\% ethanol. Stomach content samples were sorted through with prey item remains divided into smaller vials and categorized using a MZ6 Leica binocular microscope. Otoliths were measured to the nearest $0.01 \mathrm{~mm}$. When two otoliths from a given stomach were within $0.2 \mathrm{~mm}$ they were considered to originate from the same fish (Bradstreet 1980). The minimum number of fish in each stomach was calculated as the number of matched otolith pairs, plus the number of unmatched individual otoliths.

Intact zooplankton individuals, along with heads and tails for each taxon were enumerated and identified to the lowest taxonomic level possible, given the condition of the specimen

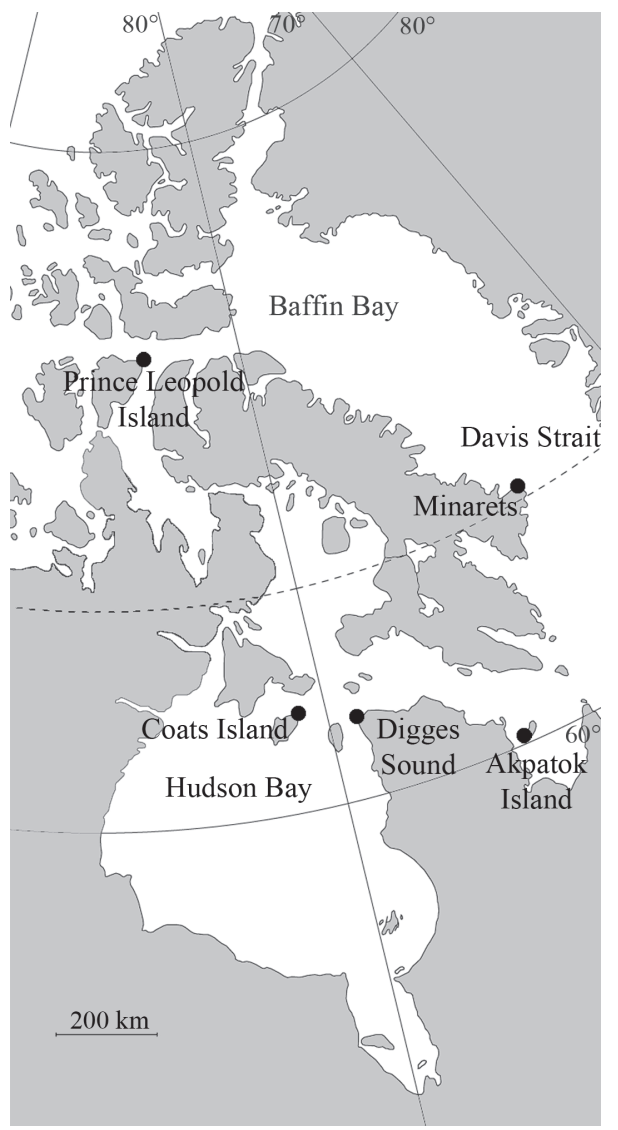

Figure 1. Map of thick-billed murre collection sites in the Canadian Archipelago. 
Table 1. Collections of adult thick-billed murres for dietary studies in the eastern Canadian Arctic.

\begin{tabular}{llcc}
\hline Colony & Collection date & $\mathrm{n}$ & \% female \\
\hline Akpatok Island & 19 August 2008 & 31 & 32 \\
Coats Island & 27 July 2007 & 25 & 96 \\
Digges Sound & 11 August 2008 & 30 & 28 \\
Digges Sound & 28 July and & 61 & 39 \\
$\quad$ 1 August 2009 & & \\
Minarets & 5 August 2007 & 30 & 47 \\
$\begin{array}{l}\text { Minarets } \\
\text { Prince Leopold } \\
\quad \text { Island }\end{array}$ & 3 August, 2008 & 20 & 15 \\
\hline & 9 Aune and & 50 & 38 \\
\hline
\end{tabular}

(Holmquist 1959, Clarke 1962, Tencati and Leung 1970, Baker et al. 1990, Klekowski and Weslawski 1991, Vinogradov et al. 1996, Audzijonyte and Vainola 2007). Abundance estimates were based on the sum of whole zooplankton and the number of isolated heads or tails, whichever was more numerous, giving a minimum number for each bird. Polycheate jaws were identified as left or right, and the number of individual polycheates present was determined from the number of either right or left jaws, whichever was greater (Gaston and Nettleship 1981,
Gaston and Bradstreet 1993). Squid numbers were estimated by the number of beak hoods or rostrums present (Gaston and Nettleship 1981, Gaston and Bradstreet 1993). GIT contents likely reflect items ingested within the last $24 \mathrm{~h}$ (Brekke and Gabrielsen 1994, Hawkins et al. 1997).

\section{Bird metrics}

Several body metrics were taken at the time of dissection, including body mass, wing length, tarsus length and three bill metrics: exposed culmen length, culmen width at nares and culmen depth at nares. Birds with wet plumage were left to dry before weighing. After the stomach contents were removed we measured intestine mass, intestine length, proventriculus mass and proventriculus length. We also examined sizecorrected mass, the residual of mass regressed on the first principal component of size (wingspan and three bill metrics).

\section{Stable isotope analysis}

At the time of dissection, breast muscle was sampled from each bird for stable isotope analysis. Samples were frozen

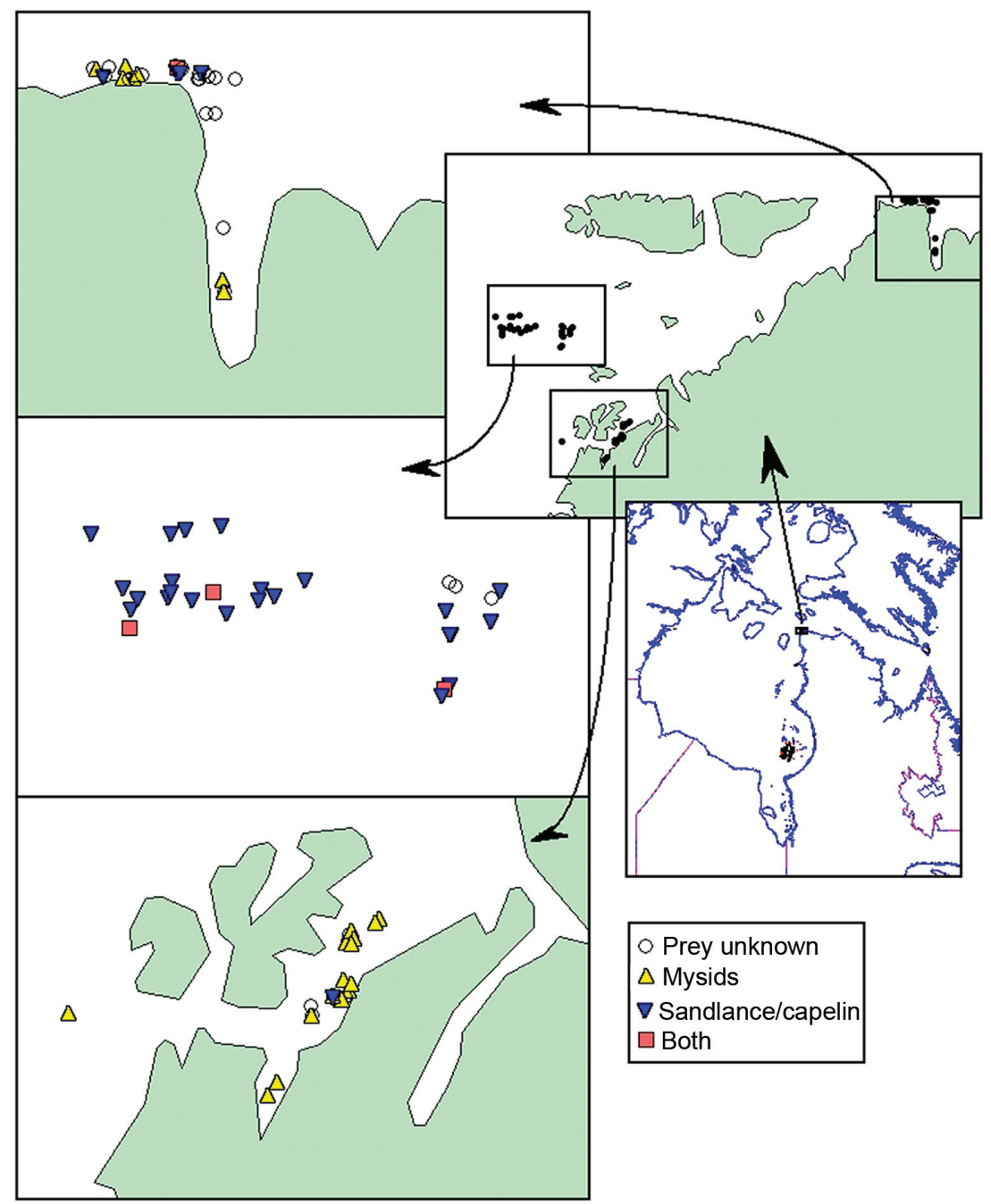

Figure 2. Distribution of murres collected in the Digges Sound region in 2008 and 2009. Individuals were classified as containing 'Mysid' if they contained evidence of more than one mysid and less than two fish otoliths, 'Sandlance/capelin' if they contained more than one otolith and less than two mysids, 'Both' if they contained more than one of each and 'Prey unknown' if they contained less than two of both groups. 
until prepared in the laboratory where lipids were extracted and then freeze-dried. Stable carbon and nitrogen isotope assays were performed for specimens from Prince Leopold, Digges Sound and Coats Island. Since oceanographic conditions differ between the sampling periods at Prince Leopold (chick-rearing versus pre-laying) we treated the two collections from Prince Leopold separately. We loaded 1 mg subsamples of homogenized materials into tin cups and combusted them at $1800^{\circ} \mathrm{C}$ in a Robo-Prep elemental analyzer. The resultant $\mathrm{CO}_{2}$ and $\mathrm{N}_{2}$ gases were then analyzed with an interfaced Europa 20:20 continuous-flow isotope ratio mass spectrometer with every five samples separated by two laboratory standards. Replicate measurements of internal laboratory standards (albumen) indicate measurement errors of $\pm 0.1 \%$ and $\pm 0.3 \%$ or for stable-carbon and nitrogen isotope measurements, respectively.

To estimate the stable isotope signature represented by each stomach sample (the ' $24 \mathrm{~h}$ predicted stable isotope value' $=\mathrm{SI}_{\mathrm{day}}$ ), we used the stable isotope ratios for lipidfree prey muscle from Hobson and Welch (1992) for Prince Leopold Island and from Woo et al. (2008) for Coats and Digges. We did not combine data from those two regions because of likely differences in baseline carbon and nitrogen isotope ratios. The foraging ranges of Coats and Digges colonies are adjacent to one another and there is no apparent difference in baseline isotope values across northeastern Hudson Bay (Pazerniuk 2007). The value was multiplied by the average mass of the prey item reported for prey collected at those colonies by Elliott and Gaston (2008):

$$
\mathrm{SI}_{24}=\Sigma\left(\mathrm{m}_{\mathrm{i}} \times \mathrm{n}_{\mathrm{i}} \times \mathrm{s}_{\mathrm{i}}\right) / \Sigma\left(\mathrm{m}_{\mathrm{i}} \times \mathrm{n}_{\mathrm{i}}\right)
$$

where $m_{i}$ is the mean mass of species $i, n_{i}$ is the number of that species found in the stomach and $s_{\mathrm{i}}$ its stable isotope ratio. We correlated $\mathrm{SI}_{24}$ against the actual measured muscle isotopic value (the 'one month stable isotope value' $=\mathrm{SI}_{\text {month }}$ ) for samples from Prince Leopold, Digges and Coats islands. Assuming 1) no measurement error in the stable isotope ratio; 2) measured prey isotope ratios represent isotope ratios of prey actually consumed by predators; 3 ) equal digestive turnover rates and equal routing of prey muscle protein into murre muscle protein content for all prey items; 4) the ratio of prey body mass to prey muscle mass is the same for all prey items; and 5) complete specialization equal to the stomach contents over the timescale of muscle turnover rates ( one month, Hobson and Clark 1992), the regression's slope and $R^{2}$ value should equal one and the regression's intercept should approximate the seabird fractionation value. Deviation from those values represents relaxation of one or more of the assumptions.

\section{Statistical analysis}

We calculated specialization indices (and null values with 10000 replicates) using IndSpec.EXE (Bolnick et al. 2002), VarIso.EXE (Araújo and Gonzaga 2007) and DietA. EXE (Araújo et al. 2008). Those programs generated random data sets constrained such that each individual had the same number of total prey items as we observed and such that the overall population dietary distribution was identical to what we determined, but that were otherwise randomly distributed. For each colony, total niche width (TNW) was calculated within IndSpec.Exe as $\sum_{j} p_{j} \ln p_{j}$, where $p_{i j}=\frac{n_{i j}}{\sum_{j} n_{i j}}$ and $n_{i j}$ is the average mass of diet items in individual is diet that falls into category $j$. The average wet mass of prey items was determined by weighing prey delivered to offspring or collected in nearby waters (Elliott and Gaston 2008). TNW can be subdivided into the between-individual component (BIC) and the within-individual component (WIC) such that TNW $=$ BIC + WIC. WIC is given by the formula $\sum_{i} p_{i}-\sum_{i} p_{i j} \ln p_{i j}$. The calculated metrics of specialization included the variation on in BIC relative to TNW (BIC/TNW), Petraitus' W (Wi) defined as $\left(\lambda_{i}\right)^{1 / \mathrm{D} i}$ where $\mathrm{D} i$ is the number of items in diet of bird $i$ and $\lambda_{i}$ is the likelihood of diet $i$, as given by the formula, $\prod_{j}\left(\frac{q_{j}}{p_{i j}}\right)^{n_{i j}}$ and the degree of niche pairwise overlap $(O)$ defined as $\frac{2 \sum w_{j k}}{n(n-1)}$ where the value $w_{j k}$ is a measure of the individual pairwise overlap between each individuals $j$ and $\mathrm{k} j$ and the summation is taken over all individuals. For chick diets, all measures of specialization were highly correlated with one another in murres (Woo et al. 2008).

A measure of clustering $\left(C_{w s}\right)$ was also generated using the value for $O$ and the network weighted clustering coefficient: $C_{w s}=\frac{C_{w}-\mathrm{O}}{O}$, where $C_{w}$ is the network weighted clustering coefficient, which is average value of the local clustering coefficient (the number of weighted edges for any given vertex divided by the total number of potential edges for that vertex) across the entire network. As explained in Araújo et al. (2008), in a totally random network $C_{u s}=0$. If individuals form discrete groups specialized on distinct sets of resources, $C_{w s}>0$. If diet variation takes place at the level of the individual, as opposed to discrete groups, then network clustering is lower than expected by chance and $C_{w s}<0$. More calculation details are available with the documentation of the programs IndSpec.EXE (Bolnick et al. 2002), VarIso.EXE (Araújo and Gonzaga 2007) and DietA.EXE (Araújo et al. 2008). To visualize networks we used the computer program Pajek. We used R 2.2.1 for all other statistical tests.

The networks represent individual murres (vertices) that are connected by edges (weighted by pairwise dietary overlap). The closer individuals are within the network, the higher the pairwise dietary overlap. Individuals that are not connected by edges have no pairwise dietary overlap. As is the case with many other studies using this technique (Bolnick et al. 2007, Araújo et al. 2008, and references therein), we base our dataset on stomach contents. Although we later examine temporal consistency of specializations by comparing stomach contents to stable isotope values, our purpose with the network analysis is to examine whether, at a single point in time, some individuals are more specialized than others. We use the overall proportion of different prey types across all individuals to create a randomized population of birds that have the same number of prey items as those observed. We then use bootstrapping to determine whether our observed degree of specialization is greater than that determined by chance alone. For instance, if four birds each ate one cod, one capelin, one sandlance and one blenny, we would consider them 'generalists' as they are no 
more specialized than expected by chance alone. In contrast, if each bird contained four fish of the same species, but in each case a different species, we would consider them 'specialists' as they are more specialized than chance alone. The network analysis is then used to determine whether there is clustering within those specializations - whether birds specializing on cod also specialize on blennies, for example.

We examined the role of niche width in determining specialization indices because those indices can be affected by niche width independent of any true specialization. For instance, a population of birds that feeds on a single prey item would have niche width of zero and specialization index of zero (there would be complete overlap between all individuals). In contrast, a population of birds that feeds on many prey items would have a high niche width and, because there would be little overlap due to chance alone, have a specialization index greater than zero. Thus, to truly account for the degree of individual specialization it is important to construct a null model for a given niche width.

To examine whether morphology was correlated with diet, we calculated dietary pairwise overlap values (proportional similarities between individuals) for each individual using IndSpec.EXE. We then correlated the dietary pairwise overlap values against the distance between and the absolute value of the difference in size of each morphological parameter for each pair of individuals. We also used t-tests to examine whether the same traits correlated with the percent of fish or crustaceans in the diet, to test the conjecture that birds with wider gapes may be adapted for feeding on crustaceans and birds with narrower gapes may be adapted for feeding on fish (Bédard 1969). To test for differences in stable isotope values between colonies, and within colonies when multiple samplings took place, we used a two-way ANOVA when normality and equal variances was met, and a two-way Wilcoxon test when they were not. We tested for normality (Shapiro-Wilk) and homogeneity of variance (Levene) prior to fitting parametric statistical models.

\section{Results}

We examined 247 murres (120 females, 144 males), containing a total of 12488 prey items. Fewer females were collected at each colony than males, except at Coats Island (Table 1). Most of the birds sampled (234) contained at least one prey item, with 213 containing one prey item that could be identified to a specific invertebrate or fish taxon. A total of 12092 identifiable prey items were found in these 213 birds (average $57 \pm 131(\mathrm{SD})$; range $=1$ to 1081 ). Stomach contents weighed $62 \pm 52 \mathrm{~g}$ on average. We considered only these 213 birds for stomach content related analyses, but include all 247 birds for comparison of body metric and stable isotope patterns.

\section{Specialization}

North-south variation in diet was evident: murres from Prince Leopold Island ate predominantly Arctic cod and those from Digges, Coats and Akpatok islands ate capelin and sandlance (Fig. 3). The majority of birds at Coats foraged on hyperiid amphipods and the majority of birds at Prince Leopold foraged on cod, leading to low niche width and low specialization (Table 2). At Minarets, Akpatok, and Digges, birds fed on a larger variety of prey, and specialization was greater (Table 2).

Across a wide variety of taxa, every population was at least slightly more specialized than chance alone (no population was more generalized than expected), although in some cases the degree of specialization was only slightly more than expected by chance alone (Table 2). Across murre colonies, the colonies with low niche width were

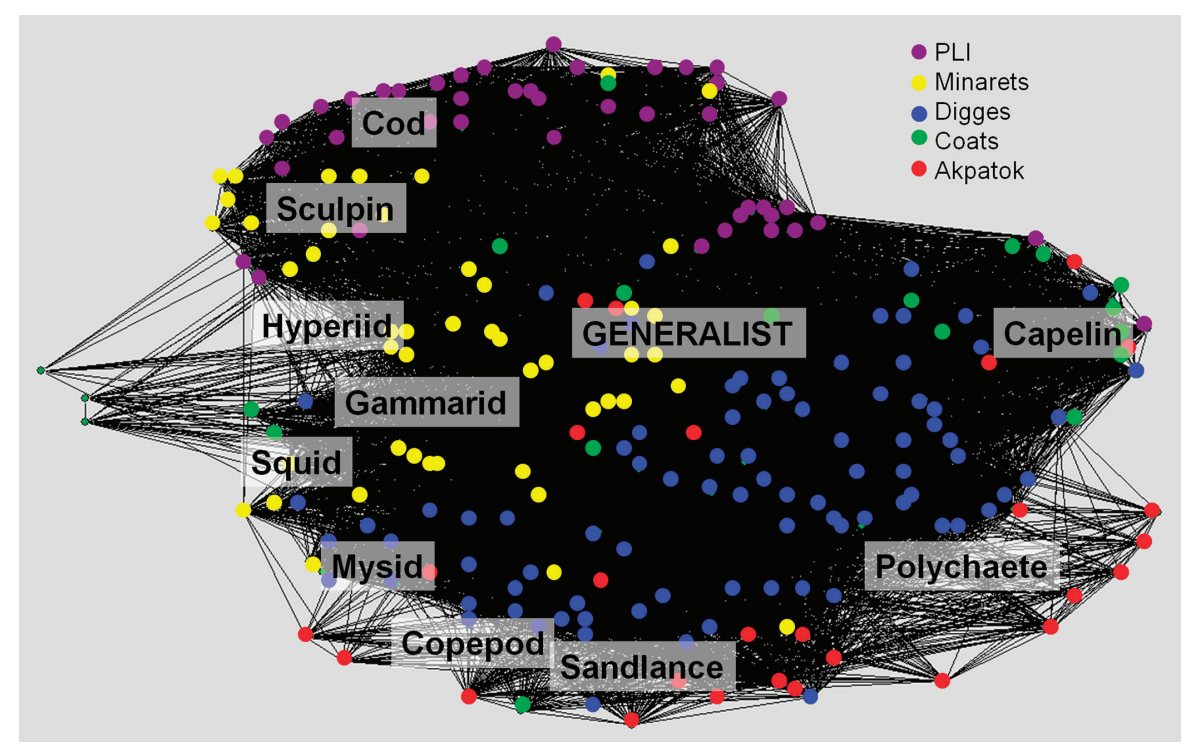

Figure 3. Foraging network for thick-billed murres collected near five colonies in the Canadian Arctic. The name for each prey item is centered on the location within the network where a complete specialist on that prey item would occur. Vertices represent individual birds while edges are weighted by the pairwise dietary similarity in stomach contents between individuals. Individuals with no dietary overlap are not connected. The network places individuals that have more heavily weighted edges in closer proximity to one another. We first calculated the pairwise overlap between each individual, and then created a position for each individual in the network based on those values. 
only slightly more specialist (greater proportional similarity) than expected by chance alone whereas those with high niche width were much more specialist than expected by chance alone (Table 2).

Diet was significantly clustered (Fig. 3, Table 2). Thus, birds feeding on one prey item tended to also feed on another. For example, birds at the Minarets containing squid also tended to contain cumacids and mysids while birds at Digges containing capelin also tended to contain sandlance and copepods (Fig. 4). Niche width and real/modelled specialization interacted $\left(F_{1,8}=6.57, \mathrm{p}=0.03\right)$ as specialization (proportional similarities) increased with niche width at a faster rate than predicted by the null model.

\section{Location}

Pairwise dietary similarity decreased weakly with distance at Akpatok $\left(t_{377}=-3.85, \mathrm{p}=0.0001, R^{2}=0.07\right)$, Digges $\left(t_{1917}=-23.5, \mathrm{p}<0.00001, R^{2}=0.25\right)$ and the Minarets $\left(t_{1128}=-4.43, \mathrm{p}<0.00001, R^{2}=0.05\right)$, but not where diet was uniform, at Coats and Prince Leopold $(\mathrm{p}>0.05$, $\left.R^{2}<0.01\right)$. For example, at Akpatok no fish were recorded in 19 stomachs collected on the northeast coast of the island while four out of nine stomachs contained fish on the northwest coast. Similarly, out of 30 stomachs from Nuvuk Harbour south of Digges Sound, only three (10\%) contained non-benthic fish and nine (30\%) contained hyperiid amphipods while out of 56 stomachs from sites closer to Digges Sound, $64 \%$ contained non-benthic fish and $78 \%$ contained hyperiid amphipods (Fig. 4). In contrast, most stomachs at Nuvuk Harbour contained mysids $(80 \%)$, polychaetes $(80 \%)$ and euphausiids (56\%) while fewer than half the stomachs from the rest of Digges Sound contained mysids $(48 \%)$, polychaetes $(44 \%)$ or euphasiids $(14 \%)$.

\section{Variation associated with sex or morphology}

The diets of the sexes were significantly clumped at the Minarets, Akpatok and Digges (Fig. 4). Specifically, the average network edge distance between females (or between males) was lower both across the entire dataset and within a single colony than in the same number of randomly selected murres (all sites: $t_{211}=6.21, \mathrm{p}<0.00001$; Minarets: $t_{46}=4.89, \mathrm{p}<0.0001 ;$ Akpatok: $t_{16}=3.73, \mathrm{p}<0.001$; Digges: $\left.t_{83}=2.96, \mathrm{p}<0.0001\right)$. Although males and females tended to clump together at the Minarets, Akpatok and
Digges, there was no difference in the proportion of any particular prey item (Fisher's exact test). There was a tendency at the Minarets for females to have more cod (Fisher's exact test $\mathrm{p}=0.13$; averaged $48 \%$ of prey by number for females compared with $12 \%$ for males) and fewer invertebrates (Fisher's exact test: $p=0.0950 \%$ for females compared with $71 \%$ for males).

There was no relationship between dietary similarity and similarity in morphology for any of the parameters examined, either when all sites were grouped or within each site separately $\left(\mathrm{p}>0.05, R^{2}<0.02\right)$. Similarly, within any site there was no correlation between any of the morphological parameters and percent of crustaceans or fish in the diet $\left(\mathrm{p}>0.05, R^{2}<0.02\right)$.

\section{Stable isotopes}

The stable isotopes of carbon and nitrogen showed different patterns among colonies when examined during the chickrearing period to control for any seasonal effects (Fig. 6; see results for Prince Leopold). At Prince Leopold Island where collections occurred during both pre-laying and chick-rearing periods there was a significant difference in both muscle $\left(\mathrm{SI}_{\text {month }}\right) \delta^{13} \mathrm{C}$ and $\delta^{15} \mathrm{~N}$ values between the two time periods (ranked T-test; $\delta^{13} \mathrm{C}: \mathrm{T}=706, \mathrm{p}<0.001 ; \delta^{15} \mathrm{~N}: \mathrm{T}=702$, $\mathrm{p}<0.001)$. At Digges where the birds were collected over a wide area, separated by as much as $40 \mathrm{~km}$, both $\mathrm{SI}_{\text {month }}$ $\delta^{13} \mathrm{C}$ and $\delta^{15} \mathrm{~N}$ values differed between sampling locales (Shapiro-Wilk $\mathrm{p}<0.05$; ANOVA on ranks $\mathrm{p}<0.001$ ). Birds were taken from three distinct sampling locations; the sheltered waters in Nuvuk Harbour, the more open waters of Hudson Bay and the exposed waters around Cape Wolstenholm. Among these three locations, the $\delta^{15} \mathrm{~N}$ values from Hudson Bay (13.84 $\pm 0.38 \%$ ), and Cape Wolstenholm $(14.13 \pm 0.30 \%$ o $)$ did not differ from each other, but both differed from the Nuvuk Harbour sample (13.19 $\pm 0.49 \%$ ) which showed significantly lower $\delta^{15} \mathrm{~N} \mathrm{SI}_{\text {month }}$ values (Dunn's method $\mathrm{p}<0.05)$. The $\delta^{13} \mathrm{C} S \mathrm{~S}_{\text {month }}$ values from all three sites differed significantly from each other (Dunn's method $\mathrm{p}<0.05$; Cape Wolstenholm $-18.91 \pm 0.37 \%$; Nuvuk Harbour $-19.37 \pm 0.22 \%$; Hudson Bay $-19.61 \pm 0.37 \%$ ) . Muscle $\delta^{15} \mathrm{~N} \mathrm{SI}_{\text {month }}$ values tended to be positively correlated with $\delta^{13} \mathrm{C}$ values (Fig. 6), except for the PLI pre-lay period, and across all of the chick-rearing sites, there were no significant differences in the slope of the $\delta^{15} \mathrm{~N}-\delta^{13} \mathrm{C}$ relationship (ANCOVA: $\mathrm{F}_{4,149}=1.22, \mathrm{p}=0.30$ ).

Table 2. Sampling of murres and specialization indices. The stomach contents (SC) collected in 2007-2009 as well as feeding watch diets from Coats Island from 2007, the year when we had stomach contents data from the same colony. The latter data were reanalyzed from the supplementary materials presented by Woo et al. (2008). Sample size shown is the number of stomach contents with the number with identifiable prey items shown in parentheses. Percent female (\% o + ) and niche width (NW) are also shown. The specialization index (BIC/TNW) calculated from the variance in muscle stable isotope values is shown in parentheses; that index could only be calculated for locations where we had prey values (Coats, Digges and Prince Leopold). A higher value for BIC/TNW, Wi and 1-Ǒ means greater specialization while a higher value of $C_{w s}$ means greater clumping.

\begin{tabular}{|c|c|c|c|c|c|c|c|c|c|}
\hline & $\mathrm{n}$ & $\%$ 우 & TNW & $\mathrm{BIC} / \mathrm{TNW}$ & Wi & $1-\check{O}$ & 1-Ǒ(nul) & $C_{w s}$ & $C_{w s}($ nul $)$ \\
\hline All murre SC & $247(213)$ & 42 & 1.27 & 0.22 & $0.21 \pm 0.02$ & $0.782 \pm 0.001$ & $0.29 \pm 0.01$ & 0.194 & $0.009 \pm 0.001$ \\
\hline Akpatok (SC) & $31(17)$ & 32 & 1.55 & 0.38 & $0.15 \pm 0.04$ & $0.713 \pm 0.002$ & $0.39 \pm 0.01$ & 0.158 & $0.143 \pm 0.008$ \\
\hline Coats (SC) & $25(19)$ & 96 & 1.08 & $0.09(0.16)$ & $0.55 \pm 0.10$ & $0.497 \pm 0.005$ & $0.05 \pm 0.01$ & 0.029 & $0.003 \pm 0.002$ \\
\hline Coats (chicks, days) & $62(62)$ & 43 & 1.81 & 0.39 & $0.40 \pm 0.03$ & $0.715 \pm 0.001$ & $0.57 \pm 0.01$ & 0.118 & $-0.011 \pm 0.004$ \\
\hline Digges (SC) & $91(86)$ & 28 & 1.94 & $0.18(0.45)$ & $0.34 \pm 0.03$ & $0.734 \pm 0.001$ & $0.64 \pm 0.02$ & 0.101 & $0.008 \pm 0.001$ \\
\hline Minarets (SC) & $50(48)$ & 34 & 1.66 & 0.17 & $0.37 \pm 0.06$ & $0.708 \pm 0.001$ & $0.17 \pm 0.01$ & 0.063 & $0.004 \pm 0.001$ \\
\hline Prince Leopold (SC) & $50(43)$ & 38 & 0.60 & $0.28(0.15)$ & $0.79 \pm 0.04$ & $0.272 \pm 0.002$ & $0.14 \pm 0.01$ & 0.007 & $0.008 \pm 0.002$ \\
\hline
\end{tabular}




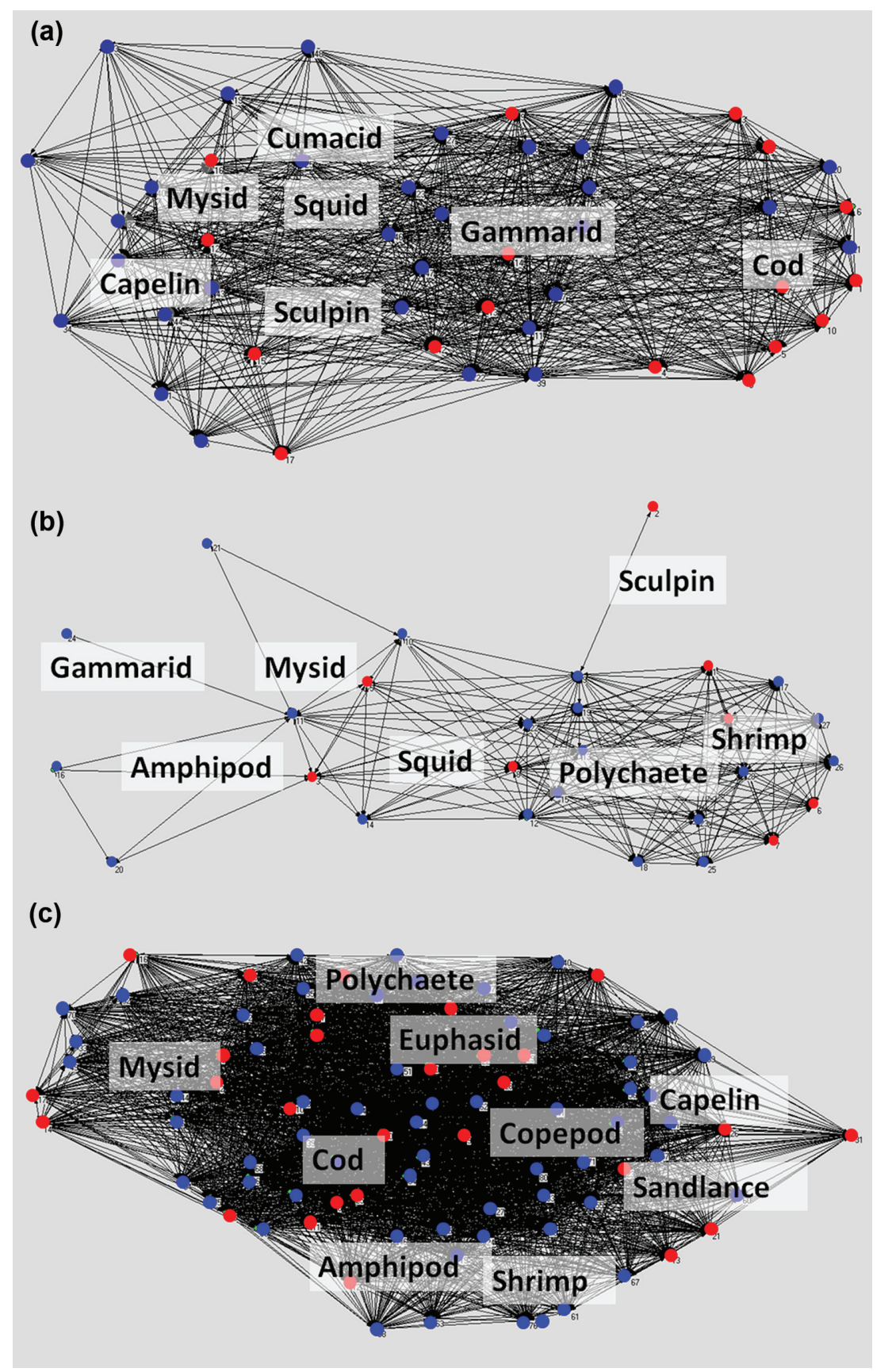

Figure 4. Foraging networks for thick-billed murres at (a) Minarets, (b) Akpatok and (c) Digges colonies in the Canadian Arctic. Red $=$ female, blue $=$ male. Vertices represent individual birds while edges are weighted by the pairwise dietary similarity between individuals. Individuals with no dietary overlap are not connected. The network places individuals that have more heavily weighed edges in closer proximity to one another.

Prey $\delta^{15} \mathrm{~N}$ values $\left(\mathrm{SI}_{\mathrm{day}}\right)$ correlated with muscle $\delta^{15} \mathrm{~N}$ $\left(\mathrm{SI}_{\text {month }}\right)$ values for the same individuals across all three sites where we obtained stable isotope values from prey samples (Coats, Digges and Prince Leopold; $t_{130}=7.06, \mathrm{p}<0.00001$, intercept $=3.04 \pm 1.48$, slope $\left.=0.84 \pm 0.11, R^{2}=0.28\right)$ and within the Digges colony $\left(t_{85}=4.05, \mathrm{p}<0.0001, R^{2}=0.14\right)$. Thus, diet over the timescale of weeks (muscle stable isotopes) correlated with diet over the timescale of hours (stomach contents). Similarly, prey $\delta^{13} \mathrm{C}$ values correlated with muscle $\delta^{13} \mathrm{C}$ values across all three sites (Coats, Digges and Prince Leopold; $t_{130}=3.82, \mathrm{p}=0.0002$, intercept $=4.14 \pm 6.21$, slope $\left.=0.77 \pm 0.34, R^{2}=0.12\right)$ and within the Digges colony $\left(t_{85}=3.21, \mathrm{p}=0.002, R^{2}=0.08\right)$. We did not analyze Coats and Prince Leopold colonies separately because they did not show substantial variation in prey isotope content.

\section{Discussion}

Consistent with previous demonstrations of individual specialization at the level of chick-provisioning in thick-billed murres (Woo et al. 2008, Elliott et al. 2009c), three different metrics (BIC/TNW, $W i$ and $\check{O}$ ) all showed that murres at 


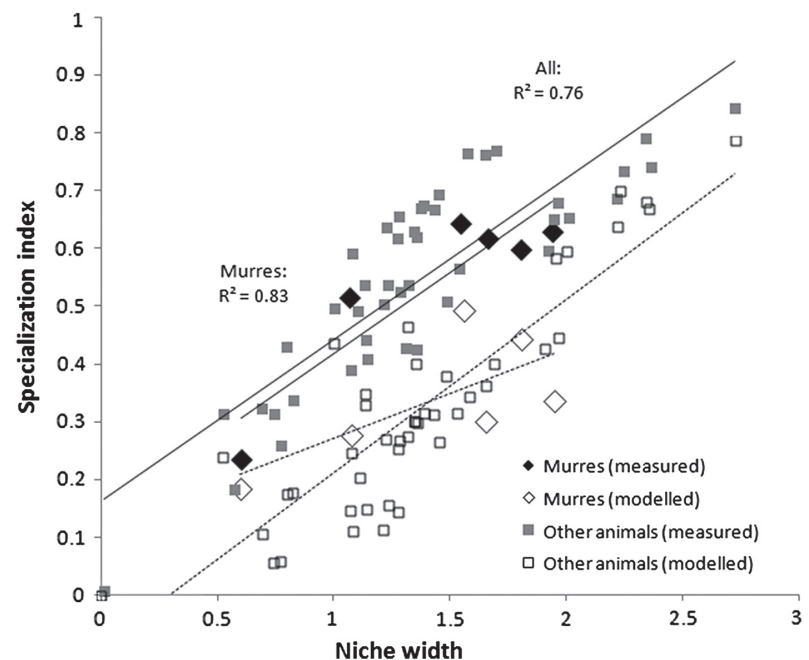

Figure 5. Specialization index (proportional similarity) in relation to total niche width. Filled symbols and solid lines represent observed values, open symbols and dotted lines are expected null model values in which diet arises solely by individuals randomly sampling a limited set of prey from a shared prey distribution. For the murre samples (large squares; 5 colonies for adult diet, plus one for chick diet) specialization index increases with niche width $\left(t_{4}=-3.03\right.$, one-tailed $\left.\mathrm{p}=0.03\right)$. Other symbols plotted are from published values: frog data from Araújo et al. (2009); sticklebacks, perch and whelk from Bolnick et al. (2007). The shorter trends lines are for the murre samples, while larger trend lines represent the regressions for the entire dataset. When all data were pooled, specialization index increased at the rate expected by chance alone.

five colonies in the Canadian Arctic demonstrated statistically significant specialization (Table 2). At the one colony where we had equivalent data on specialization during chick-provisioning (Coats Island), specialization during self-feeding (based on stomachs contents) was lower than specialization in the food fed to chicks (Table 2). Dietary similarity decreased with distance between birds at the three sites with diverse diet (Akpatok, Digges and Minarets), although relationships were weak. Possibly, birds collected nearby were opportunistically foraging on what was available at that particular place and time rather than specializing across time, meaning that apparent 'specialization' was an artefact of the sampling regime. However, that would tend to inflate our estimate of specialization and we are therefore confident with the conclusion that specialization during selffeeding was weaker than during chick-provisioning. As individual murres are known to use the same foraging locations, average flight times, dive depths and dive shapes across years, our data are also consistent with specialization during selffeeding occurring partly because prey items are clustered in space (Woo et al. 2008, Elliott et al. 2009c). In many aquatic predators individuals occur discretely in space because they specialize on either benthic or pelagic prey (Araújo et al. 2008, Garduño-Paz and Adams 2010).

Stomach contents did seem to represent individual specializations that were maintained over time, at least at Digges, the only colony where we had relevant data. The stable isotope value of stomach contents (previous 6-24 h) correlated with the muscle stable isotope value (previous month). The correlations were not particularly high as would be expected given the likelihood that several of our assumptions are violated. Namely, isotope ratios of prey we collected in northeastern Hudson Bay are likely slightly different from those that the birds actually consumed due to microscale variation, and there is likely variation in prey isotopic signatures due to size and variation in the ratio of prey body mass to prey muscle mass.

At all colonies, murre diets were more clustered than would be expected by chance alone (Table 2). A similar pattern was also present in three of the four datasets examined by others (Bolnick et al. 2007), but not in one dataset (Araújo et al. 2009). Nonetheless, when all data were pooled, specialization index increased at the rate expected by chance alone (Fig. 5).

Specialization by murres occurred in clusters within the overall networks, with several different individuals specializing on the same suite of prey items. Birds feeding in the same habitat and at the same location clustered together. Murres use stereotyped behaviour to capture particular prey items (Elliott et al. 2008). For example, Parathemisto are always caught after single, deep, V-shaped dives while Gymnelus are always caught after shallow, U-shaped dives that are part of a dive bout that includes many dives (Elliott et al. 2008). Likewise, benthic prey items are caught after extensive underwater searching with little underwater activity while pelagic

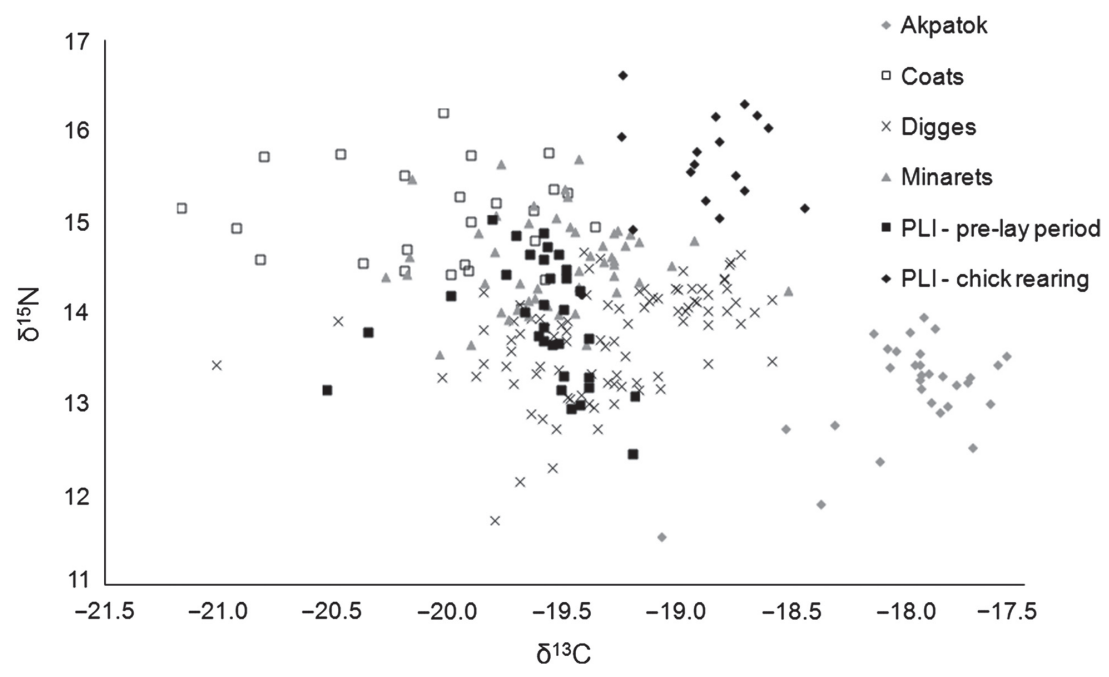

Figure 6. Stable isotope values for muscles from thick-billed murres collected in the Arctic Archipelago plotted by collection site. 
prey items are caught after extensive searching flights, but little underwater searching with more underwater activity (Elliott et al. 2009a, b, c). Thus, it is likely that birds learn and hone a particular tactic or suite of tactics, which is then used repeatedly (Woo et al. 2008).

Males and females occupied different regions of the foraging network, but there was no simple explanation for differences in prey type. There was a tendency at the Minarets for males to feed on 'risk-averse' prey (invertebrates) and females to feed on 'risk-prone' prey (cod), but patterns may have been complicated by the inclusion of non-breeding or incubating individuals; stable isotopes at Coats suggest no difference in diet during incubation (Elliott et al. 2010). Nonetheless, the presence of sex-based discrete subsets of the foraging networks supports the idea that sex-stereotyped foraging behaviour is linked to differences in diet (Lewis et al. 2002).

Stable isotope ratios varied among colonies (Fig. 6). There was no difference in the slope of the $\delta^{15} \mathrm{~N}-\delta^{13} \mathrm{C}$ relationship among sites, suggesting that the main differences were due to variation in baseline values with $\delta^{13} \mathrm{C}$ greatest at the site closest to the Atlantic Ocean (Akpatok) and lowest at the site furthest from the Atlantic Ocean (Coats) due to the effect of terrestrial runoff into Hudson Bay (also confirmed in ${ }^{13} \mathrm{C}$ measurements of invertebrates around Hudson Bay and Hudson Strait, Pazerniuk 2007). Interestingly, during the pre-lay period at Prince Leopold Island, excluding three outliers, there was a strong decline $\left(R^{2}=0.51\right)$ in $\delta^{15} \mathrm{~N}$ with increasing $\delta^{13} \mathrm{C}$. Perhaps those individuals feeding on arctic cod (with a relatively high $\delta^{15} \mathrm{~N}$ ) were also associated with carbon-depleted sea-ice food webs. Alternatively, the most recent arrivals may have only recently switched from stagingground invertebrates (low trophic level and enriched carbon associated with Atlantic input) to Arctic cod (high trophic level, depleted carbon) compared with earlier arrivals.

Similarity in morphology did not correlate with similarity in diet and the conjecture that morphological variation led to variation in diet was not upheld in our study. In particular, specializing on invertebrates was not related to larger bill gape. Similarly, phenotypic variance was not related to diet breadth in several studies spanning 32 species of birds, over 40 species of mammals and several species of frogs (reviewed by Bolnick et al. 2007, Araújo et al. 2009). The degree of variation in specialization associated with niche width in our study was similar to those found among other species, suggesting broader principles at work. Although individual specialization increased with niche width in our own study, and two studies of fish and one study of snails (Bolnick et al. 2007, but see Araújo et al. 2009), such variation in foraging ecology was not coupled with morphological variation. Nonetheless, it is always possible that other components of morphology, such as those correlating with dive capabilities (e.g. blood volume) may better predict diet. Alternatively, foraging specializations may be primarily driven by cognition or may just be a consequence of where a particular murre was first successful (exploration-refinement hypothesis, Guilford et al. 2011).

To summarize, self-feeding murres appeared to show individual specialization across time, but that specialization was lower than for chick-provisioning, likely because high flight costs mean that chick-provisioning adults must be more selective. Those specializations occurred in networks, and specialization was higher when niche width was larger. Those observations would appear to support the possibility of sympatric speciation through trophic polymorphism in seabirds (Dieckmann and Doebeli 1999, Friesen et al. 2007a, b, Woo et al. 2008): as seabirds encounter new niches, they widen their niche and individuals specializing on separate foraging networks diverge. However, we were unable to find any association between foraging networks and morphology, and so we were unable to find support for a critical component of speciation via trophic polymorphism in our populations. Thus, the morphological and genetic differentiation among murre subcolonies found at Coats Island (Ibarguchi et al. 2011) is not likely to be associated with foraging tactics.

Acknowledgements - We thank Mark Mallory, Grant Gilchrist, Steve Smith, Paul Smith, Ilya Storm, Sandy Suppa and Julia Szucs for help collecting the specimens, Guy Savard, Stacey Robinson and students from Nunavut Arctic College for assistance with dissections, Patrick O'Hara, Steffen Oppel and Yutaka Watanuki for reviewing the work and John Dower (Univ. of Victoria) who provided space and equipment for our use through his NSERC strategic funding grant. Scientific studies and collections were conducted in accordance with guidelines from the Canadian Council on Animal Care, and under appropriate territorial and federal research permits. Financial and logistic support were provided by NSERC, Environment Canada, Natural Resources Canada (PCSP), the Nattivak Hunters' and Trappers' Organization and International Polar Year 2007-2009. KHE received support from a NSERC CGSVanier Award, a Garfield-Weston Northern Studies Award, the Arctic Inst. of North America's Jennifer Robinson Scholarship and support from Sigma Xi, the Animal Behaviour Society, the Frank Chapman Fund, the American Ornithologists' Union and the Society of Canadian Ornithologists/Bird Studies Canada James Baillie Award. JFP received support from NSERC, the Arctic Inst. of North America's Grants-in-Aid program and the Northern Scientific Training Program to carry out this work.

\section{References}

Araújo, M. S. and Gonzaga, M. O. 2007. Individual specialization in the hunting wasp Trypoxylon (Trypargilum) albonigrum (Hymenoptera, Crabronidae). - Behav. Ecol. Sociobiol. 61: 1855-1863.

Araújo, M. S., Guimaraes, P. R., Svanback, R., Pinheiro, A., Guimaraes, P., Dos Reis, S. F. and Bolnick, D. I. 2008. Network analysis reveals contrasting effects of intraspecific competition on individual vs. population diets. - Ecology 89: 1981-1993.

Araújo, M. S., Bolnick, D. I., Martinelli, L. A., Giaretta, A. A. and dos Reis, S. F. 2009. Individual-level variation in four species of Brazilian frogs. - J. Anim. Ecol. 78: 848-856.

Araújo, M. S., Martins, E. G., Cruz, L. D., Fernandes, F. R., Linhares, A. X., dos Reis, S. F. and Guimaraes, P. R. 2010. Nested diets: a novel pattern of individual-level resource use. - Oikos 119: 81-88.

Audzijonyte, A. and Vainola, R. 2007. Mysis nordenskioldi n. sp (Crustacea, Mysida), a circumpolar coastal mysid separated from the NE Pacific M-litoralis (Banner, 1948). - Polar Biol. 30: 1137-1157.

Baker, A. C., Boden, B. P. and Brinton, E. 1990. A practical guide to the Euphasiids of the world. - The Natural History Museum, London.

Bédard, J. 1969. Adaptive radiation in Alcidae. - Ibis 111: 189-198.

Bolnick, D. I., Yang, L. H., Fordyce, J. A., Davis, J. M. and Svanbäck, R. 2002. Measuring individual-level resource specialization. - Ecology 83: 2936-2941. 
Bolnick, D. I., Svanbäck, R., Fordyce, J. A., Yang, L. H., Davis, J. M., Hulsey, C. D. and Forister, M. L. 2003. The ecology of individuals: incidence and implications of individual specialization. - Am. Nat. 161: 1-28.

Bolnick, D. I., Svanbäck, R., Araújo, M. S. and Persson, L. 2007. Comparative support for the niche variation hypothesis that more generalized populations are also more heterogeneous. - Proc. Natl Acad. Sci. USA 104: 10075-10079.

Bradstreet, M. S. W. 1980. Thick-billed murres and black guillemots in the Barrow Strait area, N.W.T., during spring: diets and food availability along ice edges. - Can. J. Zool. 58:2120-2140.

Brekke, B. and Gabrielsen, G. 1994. Assimilation efficiency of adult Kittiwakes and Brunnich's guillemots fed capelin and Arctic cod. - Polar Biol. 14: 279-284.

Cairns, D. K. 1987. Seabirds as indicators of marine food supplies. - Biol. Ocean. 5: 261-271.

Clarke, M. R. 1962. The identification of cephalopod 'beaks' and the relationship between beak size and total body weight. Bull. Br. Mus. (Nat. Hist.), Zool. 8: 419-480.

Cohen, R. and Havlin, S. 2010. Complex networks: structure, robustness and function. - Cambridge Univ. Press.

Dieckmann, U. and Doebeli, M. 1999. On the origin of species by sympatric speciation. - Nature 400: 354-357.

Elliott, K. H. and Gaston, A. J. 2008. Mass-length relationships and energy content of fishes and invertebrates delivered to nestling thick-billed murres Uria lomvia in the Canadian Arctic, 1981-2007. - Mar. Ornithol. 36: 25-34.

Elliott, K. H., Woo, K., Gaston, A. J., Benvenuti, S., Dall'Antonia, L. and Davoren, G. K. 2008. Seabird foraging behaviour indicates prey type. - Mar. Ecol. Prog. Ser. 354: 289-303.

Elliott, K. H., Woo, K. J. and Benvenuti, S. 2009a. Do activity costs determine foraging tactics for an arctic seabird? - Mar. Biol. 156: 1809-1816.

Elliott, K. H., Bull, R. D., Gaston, A. J. and Davoren, G. K. 2009b. Underwater and above-water search patterns of an Arctic seabird: reduced searching at small spatiotemporal scales. - Behav. Ecol. Sociobiol. 63: 1773-1785.

Elliott, K. H., Woo, K. J. and Gaston, A. J. 2009c. Specialization in murres: the story of eight specialists. - Waterbirds 32: 491-506.

Elliott, K. H., Gaston, A. J. and Crump, D. 2010. Sex-specific behaviour by a monomorphic seabird represents risk partitioning. - Behav. Ecol. 21: 1024-1032.

Friesen, V. L., Burg, T. M. and McCoy, K. D. 2007a. Mechanisms of population differentiation in seabirds. - Mol. Ecol. 16: $1765-1785$.

Friesen, V. L., Smith, A. L., Gomez-Diaz, E., Bolton, M., Furness, R. W., Gonzalez-Solis, J. and Monteiro, L. R. 2007b. Sympatric speciation by allochrony in seabird. - Proc. Natl Acad. Sci. USA 104: 18589-18594.

Garduño-Paz, M. V. and Adams, C. E. 2010. Discrete prey availability promotes foraging segregation and early divergence in Arctic charr, Salvelinus alpinus. - Hydrobiologia 650: 15-26.

Gaston, A. J. and Nettleship, D. N. 1981. The thick-billed murres of Prince Leopold Island - Environment Canada, Ottawa, ON.

Gaston, A. J. and Bradstreet, M. S. W. 1993. Intercolony differences in the summer diet of thick-billed murres in the eastern Canadian Arctic. - Can. J. Zool. 71: 1831-1840.

Gaston, A. J. and Hipfner, J. M. 2000. Thick-billed murre (Uria lomvia). - In: Poole, A. and Gill, F. (eds), The birds of North America. Cornell Univ. no. 497.

Gonzales-Solis, J., Croxall, J. P. and Wood, A. G. 2000. Sexual dimorphism and sexual segregation in foraging strategies of northern giant petrels, Macronectes halli, during incubation. - Oikos 90: 390-398.

Guilford, T., Freeman, R., Boyle, D., Dean, B., Kirk, H., Phillips, R. and Perrins, C. 2011. A dispersive migration in the Atlantic puffin and its implications for migratory navigation. - PLoS One 6: e21336.
Hawkins, P. A. J., Butler, P. J., Woakes, A. J. and Gabrielsen, G. 1997. Heat increment of feeding in Brunnich's guillemot Uria lomvia. - J. Exp. Biol. 200: 1757-1763.

Hobson, K. A. and Clark, R. G. 1992. Assessing avian diets using stable isotopes I: turnover of ${ }^{13} \mathrm{C}$ in tissues. - Condor 94: 181-188.

Hobson, K. A. and Welch, H. E. 1992. Determination of trophic relationships within a High Arctic marine food web using Delta-C-13 and Delta-N-15 analysis. - Mar. Ecol. Prog. Ser. 84: 9-18.

Holmquist, C. 1959. Problems on marine-glacial relicts on account of investigations on the genus mysis. - Berlingska and Boktryckeriet, Lund, Sweden.

Hruschka, H. and Natter, M. 1997. Comparing performance of feed forward neural nets and K-means for cluster-based market segmentation. - Eur. J. Operational Res. 114: 346-353.

Ibarguchi, G., Gaston, A. J. and Friesen, V. L. 2011. Philopatry, morphological divergence, and kin groups: structuring in thick-billed murres (Uria lomvia, Alcidae) within a colony in Arctic Canada. - J. Avian Biol. 42: 134-150.

Jain, A. K. 2009. Data clustering: 50 years beyond K-means. - In: ECML PKDD '08: Proceedings of the 2008 European Conference on Machine Learning and Knowledge Discovery in Databases - Part I. Springer, pp. 3-4.

Klekowski, R. Z. and Weslawski, J. M. (eds) 1991. Atlas of the marine fauna of southern Spitsbergen, Vol. 2. - Inst. of Oceanography, Poland.

Lewis, S., Benvenuti, S., Dall'Antonia, L., Griffiths, R., Money, L., Sherratt, T. N., Wanless, S. and Hamer, K. C. 2002. Sexspecific foraging behaviour in a monomorphic seabird. - Proc. R. Soc. B 269: 1687-1693.

MacArthur, R. H. and Pianka, E. R. 1966. On optimal use of a patchy environment. - Am. Nat. 100: 603.

Orians, G. H. and Pearson, N. E. 1979. On the theory of central place foraging. - In: Horn, D. J., Mitchell, R. D. and Stairs, G. R. (eds), Analysis of ecological systems. Ohio State Univ. Press, pp. 154-177.

Pazerniuk, M. A. 2007. Mercury and stable isotopes in the pelagic food web of Hudson Bay. - MSc thesis, Faculty of Environment, Earth and Resources, Univ. of Manitoba, Winnipeg, MB, Canada.

Provencher, J. F., Gaston, A. J., Mallory, M. L., O’Hara, P. D. and Gilchrist, H. G. 2010. Ingested plastic in a diving seabird, the thick-billed murre (Uria lomvia), in the eastern Canadian Arctic. - Mar. Pollut. Bull. 60: 1406-1411.

Provencher, J. F., Gaston, A. J., O'Hara, P. D. and Gilchrist, H. G. 2012. Seabird diet indicates changing Arctic marine communities in eastern Canada. - Mar. Ecol. Prog. Ser. 454: 171-182.

Tencati, J. R. and Leung, Y. M. 1970. Taxonomic guides to Arctic zooplankton (I): Amphipods of the central Arctic and Euphasids of the Arctic basin and peripheral seas. - Dept of Biological Sciences Univ. of Southern California, Los Angeles, CA.

Van Valen, L. 1965. Morphological variation and width of ecological niche. - Am. Nat. 99: 377-390.

Vinogradov, M., Volkov, A. and Semenova, T. 1996. Hyperid amphipods (Amphipoda, Hyperiidea) of the world's oceans. - Smithsonian Inst. Libraries, Washington, DC.

Ward, P. and Zahavi, A. 1973. Importance of certain assemblages of birds as information-centers for food-finding. - Ibis 115: 517-534.

Weimerskirch, H., Cherel, Y., Cuenot-Chaillet, F. and Ridoux, V. 1997. Alternative foraging strategies and resource allocation by male and female wandering albatrosses. - Ecology 78: 2051-2063.

Woo, K. J., Elliott, K. H., Davidson, M., Gaston, A. J. and Davoren, G. K. 2008. Individual specialization in diet by a generalist marine predator reflects specialization in foraging behaviour. - J. Anim. Ecol. 77: 1082-1091. 